Physi ol ogi cal rol es of or exi $n$ recept or s on sl eep/wakef ul ness regul at i on

\begin{tabular}{|l|l|}
\hline 著者 & M eda Mchi hi ro, Sakur ai Takeshi \\
\hline $\begin{array}{l}\text { j our nal or } \\
\text { publ i cat i on ti tl e }\end{array}$ & $\begin{array}{l}\text { Or exi } \mathrm{n} \text { and Sl eep: Mol ecul ar, Funct i onal and } \\
\text { Cl i ni cal Aspect s }\end{array}$ \\
\hline page range & $53-65$ \\
\hline year & 2015- 09-22 \\
\hline URL & ht t p: //hdl . handl e. net $/ 2297 / 44894$ \\
\hline
\end{tabular}


Physiological roles of orexin receptors on sleep/wakefulness regulation

Michihiro Mieda and Takeshi Sakurai

Department of Molecular Neuroscience and Integrative Physiology, Faculty of Medicine, Kanazawa University, Kanazawa, Ishikawa 920-8640, Japan 


\begin{abstract}
Hypothalamic neuropeptides orexin-A and orexin-B play critical roles in the regulation of sleep/wakefulness, as well as in a variety of physiological functions including emotion, reward and energy homeostasis. The effects of orexin peptides are mediated by two receptors, orexin $1(\mathrm{OX} 1 \mathrm{R})$ and orexin 2 (OX2R) receptors. These receptors show differential expression patterns depending on brain regions and neuron types, suggesting their differential roles. Here, we review the current understanding of the physiological roles of each orexin receptor subtype, focusing on the regulation of sleep/wakefulness.
\end{abstract}




\section{Orexin receptors}

The actions of orexins are mediated by two G-protein-coupled receptors, orexin 1 (OX1R) and orexin 2 (OX2R) receptors (Sakurai et al. 1998). OX1R has a one-order higher affinity for orexin-A than for orexin-B, while OX2R binds orexin- $\mathrm{A}$ and orexin-B with similar affinities. Both receptors are coupled to the $G_{q / 11}$ subclass of G-proteins and have caused strong excitatory effects on neurons examined thus far (Mieda et al. 2013), except in one study that reported the direct inhibitory action of orexin receptors on surprachiasmatic nucleus (SCN) neurons at night (Belle et al. 2014). When overexpressed, OX2R has also been reported to couple to $\mathrm{G}_{\mathrm{i} / \mathrm{o}}$ in a neuronal cell line, suggesting that OX2R could exert inhibitory action in some neurons (Zhu et al. 2003).

In clear contrast to the restricted localization of orexin mRNA expression exclusively in neurons distributed within the lateral hypothalamus (LH) and perifornical area (PFA) (Date et al. 1999; de Lecea et al. 1998; Nambu et al. 1999; Peyron et al. 1998; Sakurai et al. 1998), $O X 1 R$ and $O X 2 R$ mRNA show wide distributions within the brain with partly overlapping but distinct and complementary distributions (Marcus et al. 2001; Mieda et al. 2011). This is consistent with the fact that orexin neurons project to almost all brain areas, with especially dense ones to monoaminergic and cholinergic nuclei of the brainstem and hypothalamus, which play important roles in the regulation of sleep/wakefulness states (Chemelli et al. 1999; Nambu et al. 1999; Peyron et al. 1998). These nuclei express OX1R and OX2R in differential manners. Histaminergic neurons in the tubelomammilary nucleus (TMN) exclusively express $O X 2 R$, while noradrenergic neurons in the locus coeruleus (LC) exclusively express $O X 1 R$. In the dorsal raphe (DR) and median raphe (MnR), serotonergic neurons express $O X 1 R$ and/or 
$O X 2 R$. In the laterodorsal tegmental nucleus (LDT) and pedunculopontine tegmental nucleus (PPT), cholinergic neurons express $O X 1 R$ but not $O X 2 R$ mRNA (Marcus et al. 2001; Mieda et al. 2011). Intriguingly, there are many GABAergic neurons expressing orexin receptors which are intermingled with these monoaminergic and cholinergic neurons.

\section{Disruption of the Orexin System Causes Narcolepsy}

Degenerative loss of orexin neurons in humans is associated with narcolepsy (type I narcolepsy: narcolepsy with cataplexy), a debilitating neurological disorder, providing a unique perspective on the mechanisms of sleep/wakefulness control (Sakurai and Mieda 2011; Zeitzer et al. 2006). A series of discoveries leading to this conclusion started with findings by two animal studies: (i) functionally null mutations in the $O X 2 R$ gene were found to be responsible for familial canine narcolepsy (Lin et al. 1999), and (ii) orexin knockout mice $\left(\right.$ orexin $^{-/}$) were shown to exhibit a phenotype strikingly similar to human narcolepsy (Chemelli et al. 1999).

Human narcolepsy affects approximately 1 in 2,000 individuals in the United States (Mignot 1998; Sakurai and Mieda 2011; Zeitzer et al. 2006). The syndrome consists of excessive daytime sleepiness that often results in sleep attacks (sudden onset of non-rapid eye movement [NREM] sleep), cataplexy (sudden bilateral skeletal muscle weakening triggered by emotions, without consciousness impairment), hypnagogic hallucinations, and sleep paralysis. These symptoms can be divided into two independent pathological phenomena (Dauvilliers et al. 2007). The first is dysregulation of NREM sleep onset: the inability to maintain a consolidated awake period, characterized by abrupt transitions from wakefulness to NREM sleep. This phenomenon 
manifests clinically as excessive daytime sleepiness or sleep attacks. The second pathological phenomenon is dysregulation of rapid eye movement (REM) sleep onset: the pathological intrusion of REM sleep or REM atonia into wakefulness or at sleep onset. It is during these periods that patients may experience cataplexy, hypnagogic hallucinations, and sleep paralysis.

Similarly, orexin $^{-/}$mice display a phenotype strikingly similar to human narcolepsy, with markedly decreased duration of wakefulness episodes during the dark phase (i.e., inability to maintain a long wakeful period, or sleepiness), abrupt behavioral arrests with muscle atonia (i.e., potential cataplexy), which manifest as direct transitions from wakefulness to REM sleep in electroencephalogram/electromyogram (EEG/EMG) recordings, decreased REM sleep latency, and increased REM sleep time during the dark phase (Chemelli et al. 1999).

\section{Genetic dissection of sleep/wakefulness regulation by orexin receptors}

The fact that functionally null mutations in the $O X 2 R$ gene were responsible for two independent lines of familial narcoleptic canines indicates OX2R-mediated pathway as a critical signaling in the regulation of sleep and wakefulness (Lin et al. 1999). Studies of orexin receptor-deficient mice $\left(O X 1 R^{-/}\right.$and $O X 2 R^{-/-}$mice) have provided a deeper insight into the differential roles of OX1R and OX2R (Fig. 1)(Sakurai 2007). First, $O X 1 R^{-/} ; O X 2 R^{-/-}$mice demonstrate a narcoleptic phenotype nearly similar to that in orexin $^{-/}$mice, confirming that orexinergic regulation of sleep/wakefulness is mediated by these two receptors. $O X 1 R^{-/-}$mice show little abnormality in the states of sleep and wakefulness in the baseline condition (Hondo et al. 2010; Sakurai 2007). In contrast, $O X 2 R^{-/-}$mice have clear narcoleptic symptoms, although their phenotype is milder as 
compared to that found in orexin $^{-/-}$mice (Sakurai 2007; Willie et al. 2003). During the dark phase, $O X 2 R^{-/-}$mice did show abrupt cataplexy-like behavioral arrests, which correlated with the occurrence of direct transitions from wakefulness to REM sleep in EEG/EMG recordings (Fig. 1). However, the frequency of such arrests was far less as compared to orexin $^{-/-}$mice (31-fold lower frequency in $O X 2 R^{-/-}$mice than in orexin $^{-/-}$ mice). Importantly, close observation of the behavior of $O X 2 R^{-/}$mice during the dark phase using infrared videophotography uncovered a distinct variety of behavioral arrests with more gradual onsets (gradual arrests). Moreover, such gradual arrests turned out to also manifest in orexin $^{-/-}$mice with a frequency similar to $O X 2 R^{-/-}$mice, in addition to plenty of abrupt arrests. Abrupt and gradual arrests have been characterized as the presumptive mouse correlates of cataplexy and sleep attacks in human narcolepsy, respectively, according to their behavioral, pharmacological, and electrophysiological features (Willie et al. 2003). Consistent with this observation, wakefulness episodes of $\mathrm{OX} 2 \mathrm{R}^{-/-}$mice are fragmented to an extent similar to those of orexin $^{-/-}$mice, indicating that these two strains of mouse suffer from comparable sleepiness (Fig. 1). In contrast, $O X 2 R^{-/}$mice show normal REM sleep latency and amount of REM sleep, which are profoundly shortened and increased, respectively, in both orexin ${ }^{-/}$mice and $O X 1 R^{-/-} ; O X 2 R^{-/-}$mice (Willie et al. 2003).

Collectively, mouse reverse genetic studies suggest that the normal regulation of wakefulness and NREM sleep transitions depends critically on OX2R activation, whereas the profound dysregulation of REM sleep control unique to narcolepsy emerges from loss of signaling through both OX1R- and OX2R-dependent pathways.

This conclusion has been further confirmed by a complementary experiment, i.e., comparing the arousal effects of ICV orexin-A administration between wild-type, 
$O X 1 R^{-/}$, and $O X 2 R^{-/}$mice (Fig. 2)(Mieda et al. 2011). The effects of orexin-A on wakefulness and NREM sleep were significantly attenuated in both $O X 1 R^{-/}$and $O X 2 R^{-/-}$ mice as compared to wild-type mice, with substantially larger attenuation in $O X 2 R^{-/-}$ than in $O X 1 R^{-/-}$mice, suggesting the pivotal role of $\mathrm{OX} 2 \mathrm{R}$ and the additional role of OX1R in the promotion of wakefulness. By contrast, the suppression of REM sleep via orexin-A administration was marginally and similarly attenuated in both $O X 1 R^{-/-}$and $O X 2 R^{-/-}$mice, suggesting a comparable contribution of the two receptors to REM sleep suppression (Mieda et al. 2011). The supplementary role of OX1R in the suppression of NREM sleep is consistent with the fact that $O X 2 R^{-/-}$mice with a $\mathrm{C} 57 \mathrm{BL} / 6 \mathrm{~J}$, but not C57BL/6J-129/SvEv-mixed, genetic background show less fragmented wakefulness than orexin $^{-/-}$mice and $O X 1 R^{-/} ; O X 2 R^{-/-}$mice (Hasegawa et al. 2014; Mochizuki et al. 2011; Sakurai 2007; Willie et al. 2003), which suggests that OX1R is indispensable for the maintenance of wakefulness in the absence of OX2R.

The conclusion drawn from mouse genetics apparently contradicts the fact that an inherited canine model of narcolepsy, which demonstrates a frequent occurrence of cataplexy as well as excessive sleepiness, is attributable solely to mutations of the OX2R gene (Lin et al. 1999). Species differences (e.g., the precise expression patterns of the two orexin receptors) and/or selection bias may explain such an inconsistency. It should be noted that, even in canines, the absence of orexin peptides may cause severe narcoleptic symptoms as compared to $O X 2 R$ mutation. Early studies reported that narcoleptic Dobermans and Labradors with $O X 2 R$ mutations were much less severely affected with cataplexy than poodles with sporadic narcolepsy, which were supposed to lack orexin peptides (Baker et al. 1982). 
Sites of expression of orexin receptors relevant to the physiological control of sleep/wakefulness

The application of exogenous orexins has been shown to excite many types of neurons. Monoaminergic and cholinergic nuclei of the hypothalamus and brainstem involved in the regulation of sleep and wakefulness especially receive dense projections of orexin neurons, express orexin receptors, and are activated by the application of orexin peptides in slice preparations (Bayer et al. 2001; Brown et al. 2001; Burlet et al. 2002; Eggermann et al. 2001; Eriksson et al. 2001; Horvath et al. 1999; Liu et al. 2002; van den Pol et al. 2002; Yamanaka et al. 2002; Mieda et al. 2013). Furthermore, the administration of orexin-A directly into the LC (Bourgin et al. 2000), TMN (Huang et al. 2001), BF cholinergic area (Espana et al. 2001; Thakkar et al. 2001), and LDT (Xi et al. 2001) has also been reported to increase wakefulness. However, neurons activated by the pharmacological application of exogenous orexin may not necessarily be essential to the endogenous mechanisms by which orexin neurons regulate sleep and wakefulness in a physiological condition. Thus, neurons directly downstream from orexin neurons in physiological conditions (i.e., the site and subtype of orexin receptors that mediate the wake-promoting and REM-gating effects by endogenous orexins) have remained incompletely understood.

Histaminergic neurons in the TMN, which express OX2R exclusively, are good candidates for such downstream neurons contributing the arousal effect of orexin. Wake-promoting effect of ICV orexin-A administration is both markedly attenuated by the histamine $\mathrm{H} 1$ receptor (H1R) antagonist pyrilamine (Yamanaka et al. 2002) and is absent in $H 1 R^{-/}$mice (Huang et al. 2001). In addition, Mochizuki et al. produced OX2R-deficient mice by inserting a loxP-flanked transcription-disrupter (TD) gene 
cassette into the $O X 2 R$ gene, in which normal OX2R expression could be restored by Cre recombinase-mediated excision of TD cassette (Mochizuki et al. 2011). Using such an elegant genetic model, they showed that focal restoration of OX2R expression in the TMN and adjacent regions completely reversed the fragmentation of wakefulness episodes observed in their OX2R-deficient mice.

However, this hypothesis remains controversial. Mice lacking both OX1R and H1R demonstrate no abnormality in sleep or wakefulness, which contradicts the idea that H1R-mediated histaminergic pathway is the principal downstream component of OX2R-mediated orexinergic signaling (Hondo et al. 2010). Moreover, a recent study showed that increased probability of sleep-to-wakefulness transitions by optogenetic activation of orexin neurons does not depend on histamine (Carter et al. 2009).

Recently, we searched for monoaminergic and cholinergic nuclei of the brainstem and hypothalamus in which the focal restoration of orexin receptor expression by recombinant AAV vectors ameliorates narcoleptic phenotype of $O X 1 R^{-/} ; O X 2 R^{-/-}$ mice (Fig. 3A)(Hasegawa et al. 2014). If the regional restoration of orexin receptors in a certain brain region suppresses narcoleptic symptoms in these mice, that particular region can at least be regarded as one of the important downstream targets of orexin neurons. The targeted restoration of orexin receptor expression in the DR and LC of these mice differentially inhibited cataplexy-like episodes and the fragmentation of wakefulness (i.e., sleepiness), respectively. The suppression of cataplexy-like episodes correlated with the number of serotonergic neurons restored with orexin receptor expression in the DR, while the consolidation of fragmented wakefulness correlated with the number of noradrenergic neurons restored in the LC. Furthermore, the pharmacogenetic activation of these neurons using DREADD (designer receptor 
exclusively activated by designer drug) technology ameliorated narcolepsy in mice that lacked orexin neurons (Fig. 3B). These results suggest that DR serotonergic and LC noradrenergic neurons play differential roles in the regulation of sleep and wakefulness by orexin neurons.

The suppression of cataplexy-like episodes by DR serotonergic neurons, but not by LC noradrenergic neurons, was an unexpected result (Hasegawa et al. 2014), because previous pharmacological and electrophysiological studies suggested that LC noradrenergic neurons are good candidates for downstream neurons to prevent cataplexy. For example, drugs that increase noradrenergic tone strongly suppress cataplexy in humans and canines, while blocking the noradrenergic signaling increases the frequency of cataplexy (Hirai and Nishino 2011; Nishino and Mignot 1997). In addition, LC neurons cease firing during cataplexy in canines (Wu et al. 1999). Nevertheless, our observations never deny the clinical importance of enhancing noradrenergic systems for preventing cataplexy, yet simply indicate that the sole regulation of LC noradrenergic neurons by endogenous orexins is not sufficient to suppress cataplexy in narcoleptic mice. Non-LC noradrenergic neurons may also play an important role in the suppression of cataplexy by the pharmacological augmentation of systemic noradrenergic tone, which may be independent of the orexinergic regulation.

The contribution of orexin signaling in DR serotonergic neurons in the suppression of cataplexy fits with the observations that these neurons express both OX1R and OX2R (Mieda et al. 2011) and that the disruption of both OX1R- and OX2R-mediated pathways is required for the frequent occurrence of cataplexy, as described earlier (Sakurai 2007)(Fig. 4A). DR serotonergic neurons greatly reduce firing rates during cataplexy in canines (Wu et al. 2004). In addition, these neurons, as 
well as LC noradrenergic neurons, have been implicated in the suppression of REM sleep by inhibiting REM-on cholinergic neurons in the PPT/LDT and/or by activating REM-off GABAergic neurons in the ventrolateral periaqueductal gray (vlPAG) and adjacent lateral pontine tegmentum (LPT), also known as dorsal deep mesencephalic reticular nuclei (dDpMe) (Pace-Schott and Hobson 2002; Luppi et al. 2011). Indeed, we observed dense projections of DR serotonergic neurons to these brain areas, as well as to the amygdala (Hasegawa et al. 2014), which suggests that DR serotonergic neurons may coordinately control multiple brain regions involved in the regulation of REM sleep and emotion.

As described above, the fragmentation of wakefulness is less severe in $O X 2 R^{-/-}$mice than in orexin ${ }^{-/-}$mice and $O X 1 R^{-/} ; O X 2 R^{---}$mice with $\mathrm{C} 57 \mathrm{BL} / 6 \mathrm{~J}$ genetic background (Mochizuki et al. 2011; Sakurai 2007), suggesting that OX1R plays an important role in the maintenance of wakefulness in the absence of OX2R (Mieda et al. 2011). Indeed, restoration of $O X 1 R$ expression in the LC noradrenergic neurons of $O X 1 R^{-/} ; O X 2 R^{-/-}$mice stabilized wakefulness episodes to an extent comparable to those in $O X 2 R^{-/-}$mice (Hasegawa et al. 2014). Considering the fact that LC noradrenergic neurons exclusively express $O X 1 R$ in wild-type mice (Mieda et al. 2011), these neurons may be responsible for the contribution of OX1R to the maintenance of wakefulness, while another OX2R-mediated mechanism, most likely mediated by TMN histaminergic neurons, is further required for fully maintained wakefulness as in normal mice (Fig. 4B). Recent optogenetic studies have provided supports for the importance of the orexinergic regulation of LC noradrenergic neurons in the consolidation of wakefulness. For instance, there is a causal relationship between the firing of LC noradrenergic neurons and transitions from sleep to wakefulness (Carter et al. 2010). Moreover, the 
optogenetic inactivation of these neurons prevents the arousal effects of the optogenetic stimulation of orexin neurons (Carter et al. 2012).

\section{Pharmacological dissection of sleep/wakefulness regulation by orexin receptors}

A series of non-selective (dual) antagonists for orexin receptors (DORA), as well as subtype-selective antagonists (SORA), have been developed. On the one hand, these drugs are drawing people's attention as novel medications for insomnia and other diseases (Scammell and Winrow 2011; Sakurai 2014). On the other hand, they are also useful for studying the roles of each subtype in the regulation of sleep/wakefulness.

To a large extent, results obtained by pharmacological studies utilizing DORAs and SORAs are consistent with those derived from genetic studies described in the previous sections. Selective blockade of OX2R efficiently increases NREM sleep and shortens NREM sleep latency (Dugovic et al. 2009; Betschart et al. 2013; Dugovic et al. 2014; Etori et al. 2014; Gozzi et al. 2011). Blockade of both OX1R and OX2R does increases NREM sleep, but also causes disproportionally large increase in REM sleep (Bonaventure et al. 2015; Dugovic et al. 2009; Dugovic et al. 2014; Etori et al. 2014; Hoyer et al. 2013). Except one study showing increases in REM and NREM sleep with SB-334867 (Morairty et al. 2012), selective blockade of OX1R alone does not cause any effects with statistical significance on baseline sleep/wakefulness (Bonaventure et al. 2015; Dugovic et al. 2009; Dugovic et al. 2014; Gozzi et al. 2011; Steiner et al. 2013). Thus, OX2R is the principal regulator of wakefulness/NREM sleep transition, while both OX1R- and OX2R-mediated pathways are critical for gating REM sleep.

Administration of DORAs seldom induces cataplexy in normal animals, 
although there is a report that less than half of rats treated with high doses of SB-649868 demonstrated direct transitions from wakefulness to REM sleep (Dugovic et al. 2014). Therefore, as compared to the induction of NREM and REM sleep, nearly complete and/or chronic absence of both OX1R- and OX2R-mediated pathways may be needed for cataplexy to occur. This notion is consistent with the observation that degeneration of more than $95 \%$ of orexin neurons is required for the occurrence of cataplexy in mice, whose frequency subsequently increases along with further degeneration (Tabuchi et al. 2014).

\section{Conclusions and future directions}

Genetic and pharmacological studies have dissected the differential roles of orexin receptors in sleep/wakefulness regulation. These two approaches have both merits and demerits. Knockout mice provide clear animal models with specific and complete removal of one of two subtypes. However, chronic compensatory changes should always be taken into account. In contrast, SORAs can acutely block one of two, eliminating any compensatory effects. On the other hand, specificity, potency, efficacy, occupancy, and stability of the administered drugs should be considered.

Broad expression of orexin receptors throughout the brain complicates identifying neurons and orexin receptor subtypes directly regulated by endogenous orexins, mediating their wake-stabilizing effects. We and others have tackled this problem with a strategy of brain region/cell type-specific rescues of orexin receptors. In addition to such an approach, future studies utilizing brain region/cell type-specific genetic deletions of orexin receptors and pharmacological studies of focal administration of SORAs, as well as optogenetic and pharmacogenetic strategies, would 
further uncover the differential roles of orexin receptors and neuronal pathways downstream to orexin neurons in the regulation of sleep/wakefulness. 


\section{Figure legends}

Fig. 1. Sleep state abnormalities in orexin receptor knockout mice. Representative 12-h

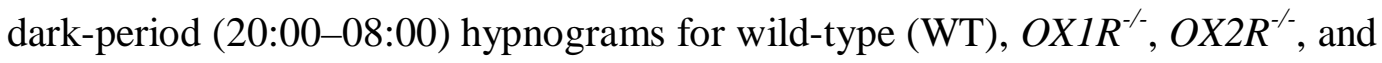
$O X 1 R^{-/} ; O X 2 R^{-/}$mice, all with a C57BL/6J background, are shown. The different levels above the baseline indicate states of sleep and wakefulness (e.g., REM, NREM, and wakefulness) of mice at the time. Episodes of direct transition from wakefulness to REM sleep are shown by arrows. Note the greater awake and NREM sleep episode fragmentation and reduced duration of wakefulness in the hypnograms of $O X 2 R^{-/}$and $O X 1 R^{-/} ; O X 2 R^{-/-}$mice compared with WT and $O X 1 R^{-/-}$mice. Episodes of direct transition from wakefulness to REM sleep were not observed in $O X 1 R^{-/-}$mice, and were hardly observed in $O X 2 R^{-/-}$mice, though they were frequently observed in $O X 1 R^{-/-}$and $O X 2 R^{-/}$mice. Modified from (Sakurai 2007).

Fig. 2. Differential effects on sleep/wakefulness states following activation of OX1R and OX2R. Dose responses of the effect of ICV orexin-A in wild-type (WT), $O X 1 R^{-/}$, $O X 2 R^{-/}$, and $O X 1 R^{-/} ; O X 2 R^{-/}$mice on time spent in wakefulness, NREM sleep, and REM sleep following administration. Modified from (Mieda et al. 2011).

Fig. 3. Search for the downstream targets of orexin neurons to prevent narcolepsy. (A) Restoration of orexin receptor expression in the DR and LC inhibits cataplexy-like episodes and consolidates wakefulness, respectively, in narcoleptic $O X 1 R^{-/-} ; O X 2 R^{-/-}$ mice. Orexin receptor expression was restored in the nuclei indicated in $O X 1 R^{-/-} ; O X 2 R^{-/-}$mice by recombinant AAV vectors. (B) Pharmacogenetic activation of DR serotonergic and LC noradrenergic neurons suppresses cataplexy-like episodes and 
consolidates wakefulness, respectively, in narcoleptic mice lacking orexin neurons (orexin/ataxin-3 mice). Orexin/ataxin-3 mice with DR serotonergic neuron-selective or LC noradrenergic neuron-selective expression of excitatory DREADD hM3Dq were injected with saline or CNO, the artificial ligand for DREADDs. Hourly plots of number of cataplexy-like episodes and mean duration of wakefulness episodes within 12 hours after saline or CNO administration at ZT 12 (arrows) are shown. Modified from (Hasegawa et al. 2014).

Fig. 4. Proposed model for OX1R- and OX2R-mediated pathways in suppressing narcoleptic symptoms. (A) Prevention of cataplexy-like episodes. (B) Consolidation of wakefulness episodes. Modified from (Hasegawa et al. 2014). 


\section{References}

Baker TL, Foutz AS, McNerney V, Mitler MM, Dement WC (1982) Canine model of narcolepsy: genetic and developmental determinants. Exp Neurol 75 (3):729-742 Bayer L, Eggermann E, Serafin M, Saint-Mleux B, Machard D, Jones B, Muhlethaler M (2001) Orexins (hypocretins) directly excite tuberomammillary neurons. Eur J Neurosci 14 (9):1571-1575

Belle MD, Hughes AT, Bechtold DA, Cunningham P, Pierucci M, Burdakov D, Piggins HD (2014) Acute suppressive and long-term phase modulation actions of orexin on the mammalian circadian clock. J Neurosci 34 (10):3607-3621. doi:10.1523/JNEUROSCI.3388-13.2014

Betschart C, Hintermann S, Behnke D, Cotesta S, Fendt M, Gee CE, Jacobson LH, Laue G, Ofner S, Chaudhari V, Badiger S, Pandit C, Wagner J, Hoyer D (2013) Identification of a novel series of orexin receptor antagonists with a distinct effect on sleep architecture for the treatment of insomnia. J Med Chem 56 (19):7590-7607. doi:10.1021/jm4007627

Bonaventure P, Yun S, Johnson PL, Shekhar A, Fitz SD, Shireman BT, Lebold TP, Nepomuceno D, Lord B, Wennerholm M, Shelton J, Carruthers N, Lovenberg T, Dugovic C (2015) A Selective Orexin-1 Receptor Antagonist Attenuates Stress-Induced Hyperarousal without Hypnotic Effects. J Pharmacol Exp Ther 352 (3):590-601. doi:10.1124/jpet.114.220392

Bourgin P, Huitron-Resendiz S, Spier AD, Fabre V, Morte B, Criado JR, Sutcliffe JG, Henriksen SJ, de Lecea L (2000) Hypocretin-1 modulates rapid eye movement sleep through activation of locus coeruleus neurons. J Neurosci 20 (20):7760-7765.

Brown RE, Sergeeva O, Eriksson KS, Haas HL (2001) Orexin A excites serotonergic neurons in the dorsal raphe nucleus of the rat. Neuropharmacology 40 (3):457-459

Burlet S, Tyler CJ, Leonard CS (2002) Direct and indirect excitation of laterodorsal tegmental neurons by Hypocretin/Orexin peptides: implications for wakefulness and narcolepsy. J Neurosci 22 (7):2862-2872. doi:20026234

Carter ME, Adamantidis A, Ohtsu H, Deisseroth K, de Lecea L (2009) Sleep homeostasis modulates hypocretin-mediated sleep-to-wake transitions. J 
Neurosci 29 (35):10939-10949. doi:10.1523/JNEUROSCI.1205-09.2009

Carter ME, Brill J, Bonnavion P, Huguenard JR, Huerta R, de Lecea L (2012) Mechanism for Hypocretin-mediated sleep-to-wake transitions. Proc Natl Acad Sci USA 109 (39):E2635-2644. doi:10.1073/pnas.1202526109

Carter ME, Yizhar O, Chikahisa S, Nguyen H, Adamantidis A, Nishino S, Deisseroth K, de Lecea L (2010) Tuning arousal with optogenetic modulation of locus coeruleus neurons. Nat Neurosci 13 (12):1526-1533. doi:10.1038/nn.2682

Chemelli RM, Willie JT, Sinton CM, Elmquist JK, Scammell T, Lee C, Richardson JA, Williams SC, Xiong Y, Kisanuki Y, Fitch TE, Nakazato M, Hammer RE, Saper CB, Yanagisawa M (1999) Narcolepsy in orexin knockout mice: molecular genetics of sleep regulation. Cell 98 (4):437-451.

Date Y, Ueta Y, Yamashita H, Yamaguchi H, Matsukura S, Kangawa K, Sakurai T, Yanagisawa M, Nakazato M (1999) Orexins, orexigenic hypothalamic peptides, interact with autonomic, neuroendocrine and neuroregulatory systems. Proc Natl Acad Sci U S A 96 (2):748-753.

Dauvilliers Y, Arnulf I, Mignot E (2007) Narcolepsy with cataplexy. Lancet 369 (9560):499-511. doi:10.1016/S0140-6736(07)60237-2

de Lecea L, Kilduff TS, Peyron C, Gao X, Foye PE, Danielson PE, Fukuhara C, Battenberg EL, Gautvik VT, Bartlett FS, 2nd, Frankel WN, van den Pol AN, Bloom FE, Gautvik KM, Sutcliffe JG (1998) The hypocretins: hypothalamus-specific peptides with neuroexcitatory activity. Proc Natl Acad Sci USA 95 (1):322-327.

Dugovic C, Shelton JE, Aluisio LE, Fraser IC, Jiang X, Sutton SW, Bonaventure P, Yun S, Li X, Lord B, Dvorak CA, Carruthers NI, Lovenberg TW (2009) Blockade of orexin-1 receptors attenuates orexin-2 receptor antagonism-induced sleep promotion in the rat. J Pharmacol Exp Ther 330 (1):142-151. doi:10.1124/jpet.109.152009

Dugovic C, Shelton JE, Yun S, Bonaventure P, Shireman BT, Lovenberg TW (2014) Orexin-1 receptor blockade dysregulates REM sleep in the presence of orexin-2 receptor antagonism. Front Neurosci 8:28. doi:10.3389/fnins.2014.00028

Eggermann E, Serafin M, Bayer L, Machard D, Saint-Mleux B, Jones BE, Muhlethaler M (2001) Orexins/hypocretins excite basal forebrain cholinergic neurones. 
Neuroscience 108 (2):177-181

Eriksson KS, Sergeeva O, Brown RE, Haas HL (2001) Orexin/hypocretin excites the histaminergic neurons of the tuberomammillary nucleus. J Neurosci 21 (23):9273-9279

Espana RA, Baldo BA, Kelley AE, Berridge CW (2001) Wake-promoting and sleep-suppressing actions of hypocretin (orexin): basal forebrain sites of action. Neuroscience 106 (4):699-715.

Etori K, Saito YC, Tsujino N, Sakurai T (2014) Effects of a newly developed potent orexin-2 receptor-selective antagonist, compound $1 \mathrm{~m}$, on sleep/wakefulness states in mice. Front Neurosci 8:8. doi:10.3389/fnins.2014.00008

Gozzi A, Turrini G, Piccoli L, Massagrande M, Amantini D, Antolini M, Martinelli P, Cesari N, Montanari D, Tessari M, Corsi M, Bifone A (2011) Functional magnetic resonance imaging reveals different neural substrates for the effects of orexin-1 and orexin-2 receptor antagonists. PLoS One 6 (1):e16406. doi:10.1371/journal.pone.0016406

Hasegawa E, Yanagisawa M, Sakurai T, Mieda M (2014) Orexin neurons suppress narcolepsy via 2 distinct efferent pathways. J Clin Invest 124 (2):604-616. doi:10.1172/JCI71017

Hirai N, Nishino S (2011) Recent advances in the treatment of narcolepsy. Current treatment options in neurology 13 (5):437-457. doi:10.1007/s11940-011-0137-6

Hondo M, Nagai K, Ohno K, Kisanuki Y, Willie JT, Watanabe T, Yanagisawa M, Sakurai T (2010) Histamine-1 receptor is not required as a downstream effector of orexin-2 receptor in maintenance of basal sleep/wake states. Acta Physiol 198 (3):287-294. doi:10.1111/j.1748-1716.2009.02032.x

Horvath TL, Peyron C, Diano S, Ivanov A, Aston-Jones G, Kilduff TS, van Den Pol AN (1999) Hypocretin (orexin) activation and synaptic innervation of the locus coeruleus noradrenergic system. J Comp Neurol 415 (2):145-159

Hoyer D, Durst T, Fendt M, Jacobson LH, Betschart C, Hintermann S, Behnke D, Cotesta S, Laue G, Ofner S, Legangneux E, Gee CE (2013) Distinct effects of IPSU and suvorexant on mouse sleep architecture. Front Neurosci 7:235. doi:10.3389/fnins.2013.00235

Huang ZL, Qu WM, Li WD, Mochizuki T, Eguchi N, Watanabe T, Urade Y, Hayaishi O 
(2001) Arousal effect of orexin A depends on activation of the histaminergic system. Proc Natl Acad Sci U S A 98 (17):9965-9970. Epub 2001 Aug 9967.

Lin L, Faraco J, Li R, Kadotani H, Rogers W, Lin X, Qiu X, de Jong PJ, Nishino S, Mignot E (1999) The sleep disorder canine narcolepsy is caused by a mutation in the hypocretin (orexin) receptor 2 gene. Cell 98 (3):365-376.

Liu RJ, van den Pol AN, Aghajanian GK (2002) Hypocretins (orexins) regulate serotonin neurons in the dorsal raphe nucleus by excitatory direct and inhibitory indirect actions. J Neurosci 22 (21):9453-9464

Luppi PH, Clement O, Sapin E, Gervasoni D, Peyron C, Leger L, Salvert D, Fort P (2011) The neuronal network responsible for paradoxical sleep and its dysfunctions causing narcolepsy and rapid eye movement (REM) behavior disorder. Sleep Med Rev 15 (3):153-163. doi:10.1016/j.smrv.2010.08.002

Marcus JN, Aschkenasi CJ, Lee CE, Chemelli RM, Saper CB, Yanagisawa M, Elmquist JK (2001) Differential expression of orexin receptors 1 and 2 in the rat brain. J Comp Neurol 435 (1):6-25.

Mieda M, Hasegawa E, Kisanuki YY, Sinton CM, Yanagisawa M, Sakurai T (2011) Differential roles of orexin receptor- 1 and -2 in the regulation of non-REM and REM sleep. J Neurosci $31 \quad$ (17):6518-6526. doi:10.1523/JNEUROSCI.6506-10.2011

Mieda M, Tsujino N, Sakurai T (2013) Differential roles of orexin receptors in the regulation of sleep/wakefulness. Front Endocrinol (Lausanne) 4:57. doi:10.3389/fendo.2013.00057

Mignot E (1998) Genetic and familial aspects of narcolepsy. Neurology 50 (2 Suppl 1):S16-22.

Mochizuki T, Arrigoni E, Marcus JN, Clark EL, Yamamoto M, Honer M, Borroni E, Lowell BB, Elmquist JK, Scammell TE (2011) Orexin receptor 2 expression in the posterior hypothalamus rescues sleepiness in narcoleptic mice. Proc Natl Acad Sci U S A 108 (11):4471-4476. doi:10.1073/pnas.1012456108

Morairty SR, Revel FG, Malherbe P, Moreau JL, Valladao D, Wettstein JG, Kilduff TS, Borroni E (2012) Dual hypocretin receptor antagonism is more effective for sleep promotion than antagonism of either receptor alone. PloS one 7 (7):e39131. doi:10.1371/journal.pone.0039131 
Nambu T, Sakurai T, Mizukami K, Hosoya Y, Yanagisawa M, Goto K (1999) Distribution of orexin neurons in the adult rat brain. Brain Res 827 (1-2):243-260.

Nishino S, Mignot E (1997) Pharmacological aspects of human and canine narcolepsy. Prog Neurobiol 52 (1):27-78

Pace-Schott EF, Hobson JA (2002) The neurobiology of sleep: genetics, cellular physiology and subcortical networks. Nature reviews Neuroscience 3 (8):591-605. doi:10.1038/nrn895

Peyron C, Tighe DK, van den Pol AN, de Lecea L, Heller HC, Sutcliffe JG, Kilduff TS (1998) Neurons containing hypocretin (orexin) project to multiple neuronal systems. J Neurosci 18 (23):9996-10015.

Sakurai T (2007) The neural circuit of orexin (hypocretin): maintaining sleep and wakefulness. Nature reviews Neuroscience 8 (3):171-181. doi:10.1038/nrn2092

Sakurai T (2014) The role of orexin in motivated behaviours. Nat Rev Neurosci 15 (11):719-731. doi:10.1038/nrn3837

Sakurai T, Amemiya A, Ishii M, Matsuzaki I, Chemelli RM, Tanaka H, Williams SC, Richardson JA, Kozlowski GP, Wilson S, Arch JR, Buckingham RE, Haynes AC, Carr SA, Annan RS, McNulty DE, Liu WS, Terrett JA, Elshourbagy NA, Bergsma DJ, Yanagisawa M (1998) Orexins and orexin receptors: a family of hypothalamic neuropeptides and $G$ protein-coupled receptors that regulate feeding behavior. Cell 92 (4):573-585.

Sakurai T, Mieda M (2011) Connectomics of orexin-producing neurons: interface of systems of emotion, energy homeostasis and arousal. Trends Pharmacol Sci 32 (8):451-462. doi:10.1016/j.tips.2011.03.007

Scammell TE, Winrow CJ (2011) Orexin receptors: pharmacology and therapeutic opportunities. Annual review of pharmacology and toxicology 51:243-266. doi:10.1146/annurev-pharmtox-010510-100528

Steiner MA, Gatfield J, Brisbare-Roch C, Dietrich H, Treiber A, Jenck F, Boss C (2013) Discovery and characterization of ACT-335827, an orally available, brain penetrant orexin receptor type 1 selective antagonist. ChemMedChem 8 (6):898-903. doi:10.1002/cmdc.201300003

Tabuchi S, Tsunematsu T, Black SW, Tominaga M, Maruyama M, Takagi K, Minokoshi 
Y, Sakurai T, Kilduff TS, Yamanaka A (2014) Conditional ablation of orexin/hypocretin neurons: a new mouse model for the study of narcolepsy and orexin system function. J Neurosci 34 (19):6495-6509. doi:10.1523/JNEUROSCI.0073-14.2014

Thakkar MM, Ramesh V, Strecker RE, McCarley RW (2001) Microdialysis perfusion of orexin-A in the basal forebrain increases wakefulness in freely behaving rats. Arch Ital Biol 139 (3):313-328

van den Pol AN, Ghosh PK, Liu RJ, Li Y, Aghajanian GK, Gao XB (2002) Hypocretin (orexin) enhances neuron activity and cell synchrony in developing mouse GFP-expressing locus coeruleus. J Physiol 541 (Pt 1):169-185.

Willie JT, Chemelli RM, Sinton CM, Tokita S, Williams SC, Kisanuki YY, Marcus JN, Lee C, Elmquist JK, Kohlmeier KA, Leonard CS, Richardson JA, Hammer RE, Yanagisawa M (2003) Distinct narcolepsy syndromes in Orexin receptor-2 and Orexin null mice: molecular genetic dissection of Non-REM and REM sleep regulatory processes. Neuron 38 (5):715-730

Wu M, Zaborszky L, Hajszan T, van den Pol AN, Alreja M (2004) Hypocretin/orexin innervation and excitation of identified septohippocampal cholinergic neurons. The Journal of neuroscience : the official journal of the Society for Neuroscience 24 (14):3527-3536. doi:10.1523/JNEUROSCI.5364-03.2004

Wu MF, Gulyani SA, Yau E, Mignot E, Phan B, Siegel JM (1999) Locus coeruleus neurons: cessation of activity during cataplexy. Neuroscience 91 (4):1389-1399

Xi MC, Morales FR, Chase MH (2001) Effects on sleep and wakefulness of the injection of hypocretin-1 (orexin-A) into the laterodorsal tegmental nucleus of the cat. Brain Res 901 (1-2):259-264.

Yamanaka A, Tsujino N, Funahashi H, Honda K, Guan JL, Wang QP, Tominaga M, Goto K, Shioda S, Sakurai T (2002) Orexins activate histaminergic neurons via the orexin 2 receptor. Biochem Biophys Res Commun 290 (4):1237-1245.

Zeitzer JM, Nishino S, Mignot E (2006) The neurobiology of hypocretins (orexins), narcolepsy and related therapeutic interventions. Trends Pharmacol Sci 27 (7):368-374.

Zhu Y, Miwa Y, Yamanaka A, Yada T, Shibahara M, Abe Y, Sakurai T, Goto K (2003) Orexin receptor type-1 couples exclusively to pertussis toxin-insensitive 
G-proteins, while orexin receptor type-2 couples to both pertussis toxin-sensitive and -insensitive G-proteins. Journal of pharmacological sciences 92 (3):259-266 


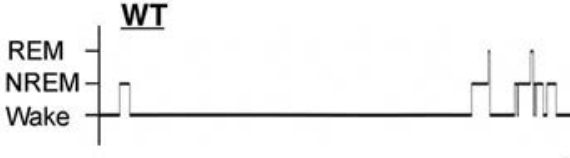


Wakefulness

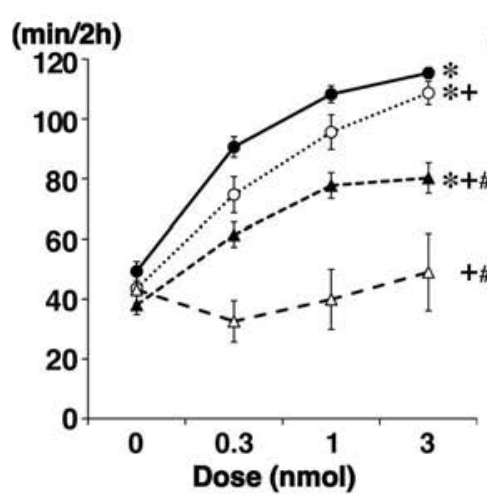

NREM sleep

REM sleep

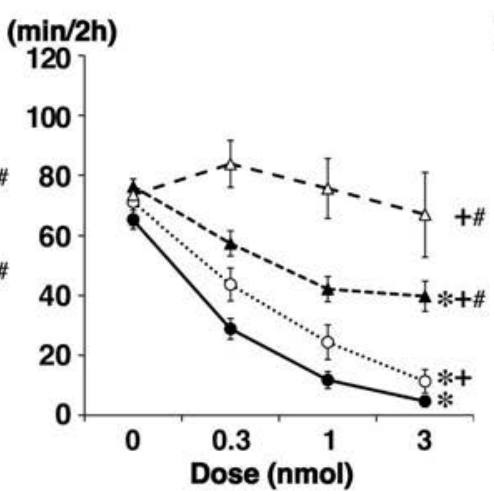

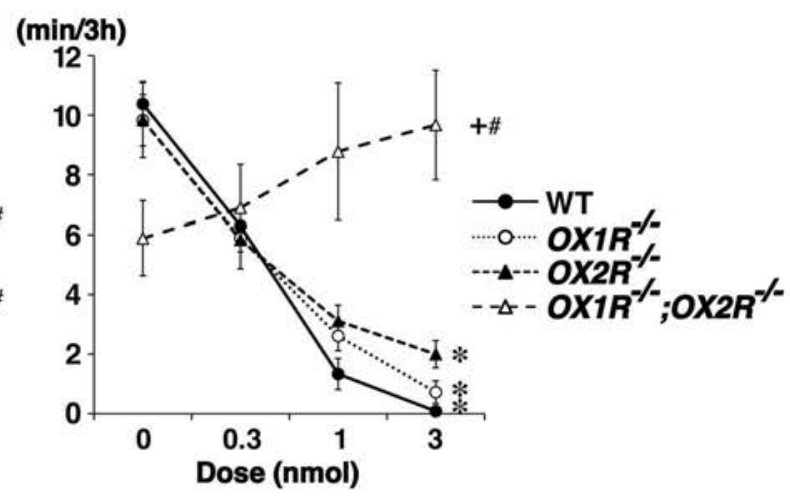


Frequency of cataplexylike episodes

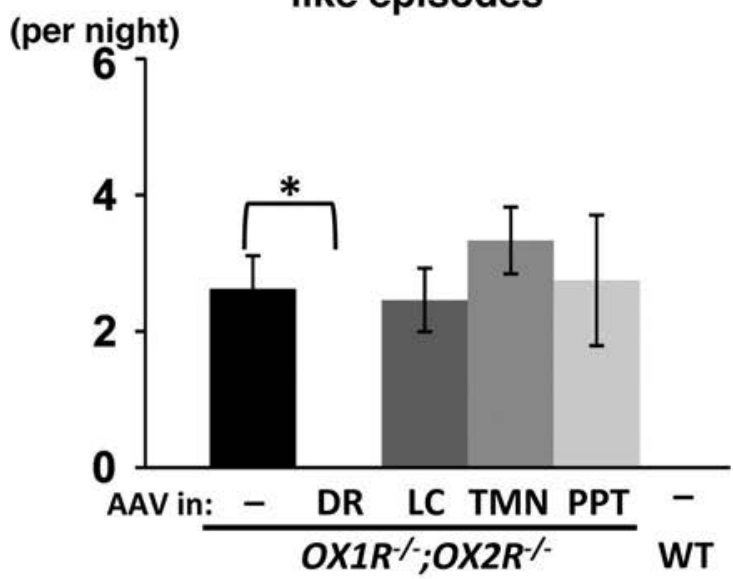

hM3Dq in:

Frequency of cataplexy-like episodes

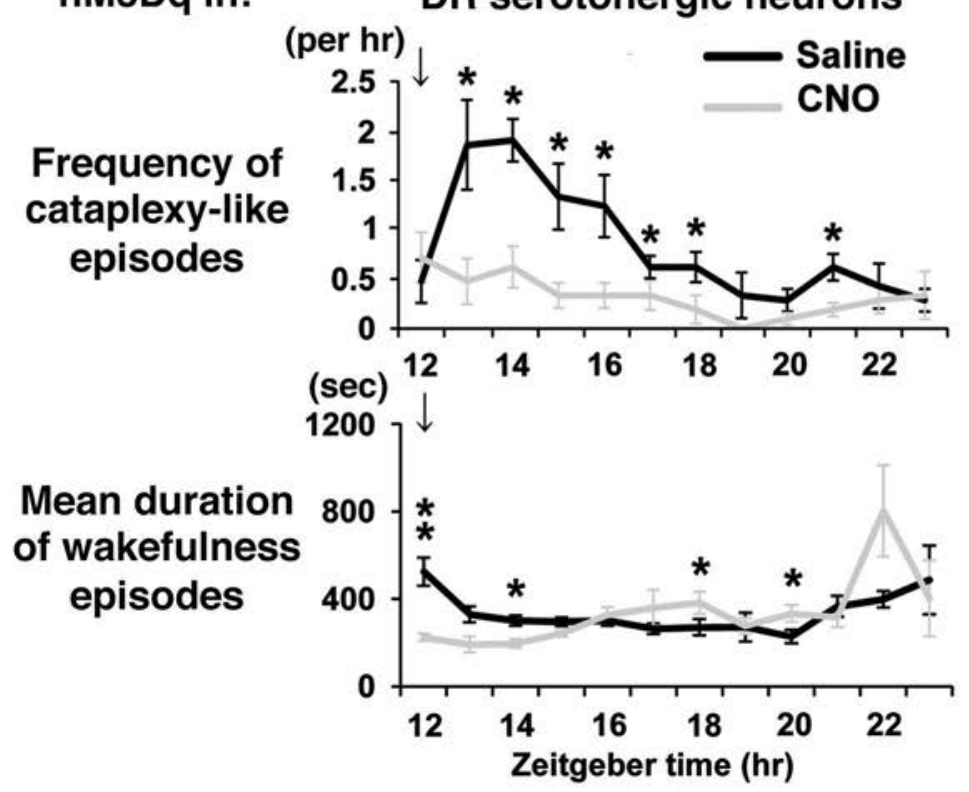

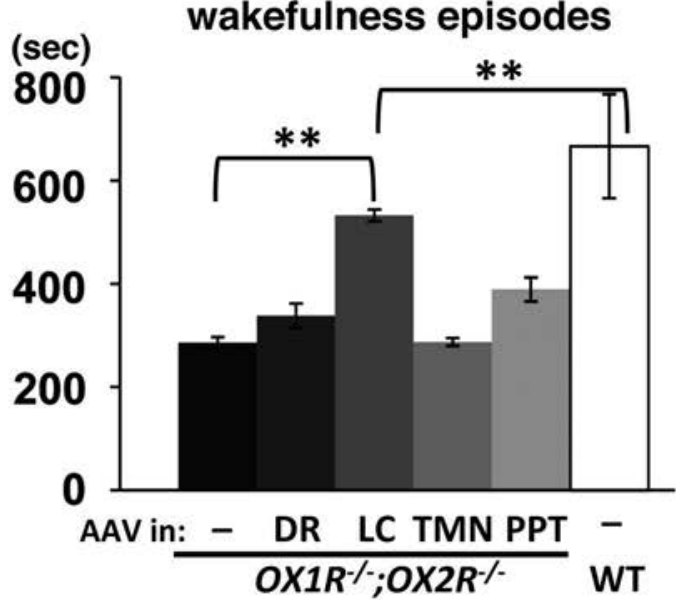

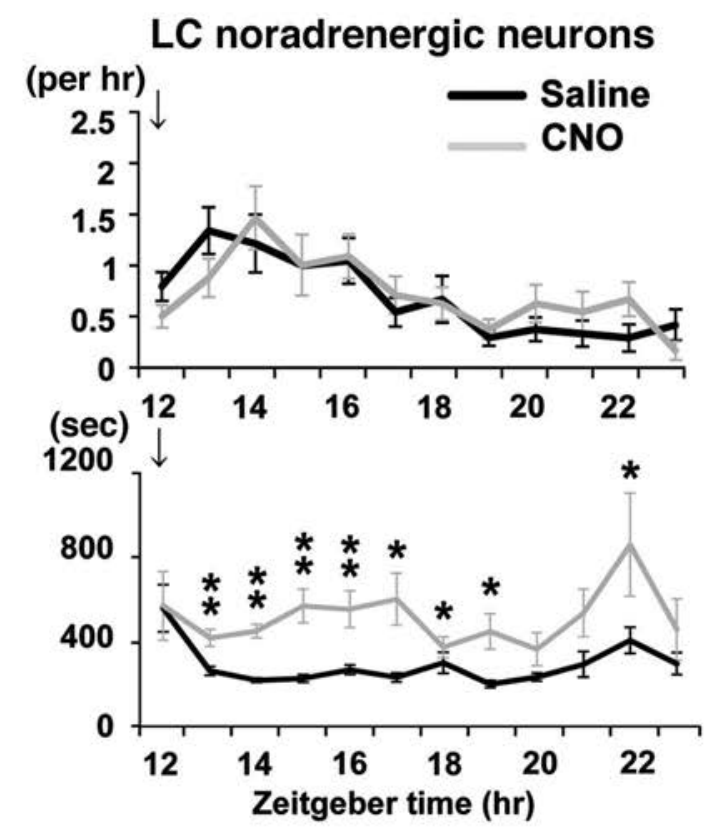


